\title{
Cultural Bound Syndrome: A Case of Iyol-Genen among Females of Tiv Origin in Nigeria.
}

\author{
Labe Ransome Msughve, Chia, Perptua Ngosoo, Kuzah, Martins Terseer and \\ Shimakaa, Andrew Iorlumun
}

\begin{abstract}
This study examined "Iyol-genen" and presents it as an appraisal of the concept of Cultural-Bound syndrome which in Tiv society is a specific gender related psychotic-like reactive disorder prevalent among women from their puberty to adulthood. The research adopted a qualitative general survey approach of interview to determine that the disorder is a cultural bound syndrome affecting only women in the Tiv ethnic group. A total of 40 selected women participants age 13 to 35 that experiences this disorder were interviewed. In the analysis of the respondent's information, it was found that Iyol-genen, which predominantly affects women, has genetic linkage which was confirmed from two different identical twin sisters as well as sisters of the same parents.It is also a genealogical psychopathological disorder which peculiarly disturbssomewomen from particular families in all parts of the Tiv geographical location. This may be linked to the Tiv ancestral connection as they share similar ancestral characteristics. The disorder has no specific medication be it traditional or orthodox for treatment and cure but self-remitting. However, different people give different things such as holy water, squeezed sap of "Vambe" or powder charcoal mixed in water at the instance of each episode of the disorder which often coincidently restores the patient to normality. It is therefore the position of this study to recommend for further research to identify the why and what precipitate Iyol-genen in only female population living out men who are also Tiv and to develop a treatment that will help to reduce the demoralizing mental health problem.
\end{abstract}

Keywords: Iyol-genen, women and cultural-bound syndrome

\section{Introduction}

Trying to define mental illness and distress is not a straightforward process as there are many different views, theories and experiences which define for us the nature and causes of mental health (Murphy, 2006). People use different words and terminology across culture and society to describe what is happening to themselves or people close to them when a behaviour or action is not understood within what is normal within a society's culture. Therefore the concept of what is normal can then be dependent on who is doing the definition. Beyond the boundaries of debate on the definition of mental illness, mental disorder or mental illness is a psychological or behavioural pattern generally associated with subjective distress or disability that occurs in an individual, and which is not a part of normal development or culture(korchin, 2004).

Furthermore, the cause of mental illness is not easily defined unlike many physical illnesses that have defined identifiable causes. Different factors are examined and analysed for the purpose of understanding why people developed mental health problems and this resulted into the integration of diversified approaches into a model called biopsychosocial popularized by Engel (1977). This is because it suggests that we should consider any of the following factors such as specific medical problem, bio-chemical or genetic factors, personality, learned behaviour, stress vulnerability or relationship difficulties are present.

Contrary, people in different cultural and social groups explain and view causes of ill health, types of treatment they get in different ways. These ways may not match with how the medical and mental health professional sees it. The approach for seeking help may take in account wider socio-cultural and religious factors as confirmed by Lambo 1960; 1965; Murphy, 1982; Pfeifer, 1994 cited in (Jilek, 2001). Culturally based signs and symptoms of mental distress or maladaptive behaviour are observed and explained in folk belief and practice" (Sadock\&Sadock, 2003).Such patterns are informed by native cultural assumptions, sorcery, break of taboo, intrusion of a disease-causing spirit, or loss of soul this results from both natural and unnatural causes having sources of external and internal factors which includes spirit possession, witchcraft, hostile ancestral spirits, divine retribution, evil machination, intrusion of objects, disturbance in social relationship, affliction by gods (Idumedia, 2004;Sadock\&Sodock, 2003). There is variation across cultures with regard to the nature, meaning, experience, and evaluation of the mental problems.Thus, the broad spectrum of views from psychiatrist and psychologists, the submission is that cultural relativity predicts mental disorder and culturalbound syndrome and moreover, African prefers to use treatments that recognize their ways of thinking and values system (Idumedia, 2004;Sadock\&Sodock, 2003). 
Social-cultural perspective to mental disorder has stimulated the evolution of the concept of cultural bound syndrome or disorder which is used interchangeably.The term culture-bound syndrome denotes recurrent, locality-specific patterns of aberrant behaviour and troubling experience that may or may not be linked to a particular DSM-IVdiagnostic category. Many of these patterns are indigenously considered to be "illnesses," or at least afflictions and most have local names (Guarnaccia\&Rogler, 1999).Jilek (2001) in his paper has reported that the term and the concept of Cultural bound-Reactive Syndrome was introduced in the 1960 by Pow Yap (Yap, 1969a; b) and several conditions have since been cited in the literature under a variety of indigenous names and are defined as episodic and dramatic reactions specific to a particular community-locally defined as discreet patterns of behaviour (Hughes, 1985; Littlewood\&Lipsedge, 1985). Around the turn of the 20th century, during a period of colonization by western societies, western missionaries, physicians, and others visited faraway countries, where they encountered behaviours and unique psychiatric conditions that they had never experienced in their homelands, and labeled them 'peculiar' phenomenon (Wein-Shing Tseng, 2006). Most of these conditions were known to the local people by folk names, and even treatment. In 1948, Gillin elaborated on magical fright in the Journal of Psychiatry; in 1957, Cannon reported on 'voodoo' death in Psychosomatic Medicine; in 1959, Fernández-Marian mentioned a Puerto Ricansyndrome known later as ataques de nervios; in 1960, some are listed in a DSM-4 Glossary and in the ICD-10 Diagnostic Criteria for research. Among the terms listed are universally occurring dysphoric and anxiety reaction with various somatoform symptoms, known in a particular culture under a local name that designates them as appropriate for special treatment by traditional healers (Jilek, 2001). However, Hughes (1996) proposed that these disorders form a unique and distinctive class of generic phenomenon and that such syndrome exist among and afflict only the "other" people who by some criterion are outside the mainstream population.

Cultural bound-syndrome is a term used to describe the uniqueness of some mental disorder in specific cultures. Psychiatry and psychology literature has identified social stress situations and geographical location as causative factors. Prince and Tcheng-Laroche (1987) emphasized that four facts of cultural-bound syndromes must be taken into account when studying them. These are accidents of geography (i.e. a disorder may be presented in some culture but not in others for geographical rather than social reasons). In Third World, acute transient psychotic-like reaction is known to be more common than schizophrenia; they appear to occur especially frequently in African population (Jilek\&Jilek- Aall, 1970). Jilek (2001) further stated that the clinical picture of these reactions has been described in detail by francophone psychiatrists working in Africa and by Latin American psychiatrists (Bustamante, 1969; Collomb, 1965; Magnan, 1886; Rainut 1958; Salles, 1961; Villasenor Bayardo, 1993; Vyncke, 1957). A variety of diagnostic labels has been attached by Anglophone authors to designate these transitory psychotic disorders, but increasingly the designate these transitory psychotic disorders, but increasingly the French term bouffée délirante, introduced by Magnan in 1886, is to designate transient psychotic or psychosis -like reactions. ACanadian culturalpsychiatrist, Raymond Princein 1960 after his field experience with students in Nigeria and other African countries,reported on the 'brain fag' syndrome; a renowned Professor of psychiatry Lambo Adeoye in 1962 from Africa, after studying inEurope and returning to his home country, described and named the phenomenon of malignant anxiety in Africa; in 1964, (Jilek, 2001).

Further research conducted in Nigeria revealed the concept of "Ode Ori" (Makanjuola, 1987)"Ogun Oru" was only recently was confirmed by Aina and Famuyiwa (2007) study. In Lagos, the commercial capital and the most populous city in Nigeria, the typical alarm was "Ole! Oko mi ti loo" ("Thief! My genitals are gone!"). Also "abiku" (among the Yoruba) and the concept of Ogban-njeparticularly among females of Igbo origin ispathological reincarnation which explain most form of mental illness/possession (Aina\&Morakinyo, 2011; Idumedia, 2004). Some culture-specific syndromes involve somatic symptoms (pain or disturbed function of a body part), while others are purely behaviouralwith sudden attacks of brief duration characterized by paranoid delusions and concomitant hallucinations, typical believed to be confusional state highly emotional behaviour and after attack, by amnesia, or rather disavowal (Jilek, 2001).

Extrapolating from the chronicle of the empirical history of cultural bound syndrome, it is sustainably clear that a number of CBS have been described among West Africans most of which are yet to be incorporated in the internationally accepted classificatory systems(Ayonrinde, 1977; Majudina\&Attah-Johnson 1984). And others better still have remained unknown. Based on theknowledge of socio-cultural pedigreeto mental health and illness that this paper seeks to report the existing of Iyol-genen as a cultural bound disorder which specifically affect Tiv females in Benue North-Central part of Nigeria.

Iyol-genen literary translated as (Body Disruption) is a transient and episodic psychotic-like reaction which is affecting only women in Tiv in Benue North-central part of Nigeria.This disorder is typically characterised by

Chest pain,

Aching teeth

Disorientation 
Muteness

Restlessness

Hearing of voices and seen things indescribable (auditory/visual hallucination)

Running away to no specified direction (Confusion)

Screaming and shouting

Stripping off of clothes worn

It is a known fact that both men and women can be affected by a psychological or psychiatric disorderexcept forsome mental disorders whose observed statistical significant difference showsthat one gender group suffering more than the other.Despite this, the concern preoccupying our thinking is that why Iyol-genenis a cultural bound syndrome that predominantly affects only women and mostly in their transitional period from puberty to adulthood?Is this disorder a genetic transmitted mental health problem from the Tiv ancestral genealogy? Is there particular gene /hormone that predisposed some women in particular families to Iyol-genen and not men among Tiv people in Benue state?

Besides, these three major reasons put forward by the cited authors has influence the focus of this research on Iyol-genen as a culture-bound syndrome. The first is the increasing cultural diversity of persons seeking mental health care, which reflects the increasing cultural diversity of societies like Nigeria. Clinicians who serve an increasingly culturally diverse population need to know more about such syndromes (Maser, Kaelber\& Weise, 1991).

The second reason for focusing research on culture bound syndromes is that the editions of DSM have become international documents (Guarnaccia\& Rodriguez, 1996). However, editions of the manual before DSM-IV included little material that reflected the scope of cross-cultural diversity of psychiatric problems, therefore, the need to comprehensively include other cultural bound disorders that are discovered and reported by scholars in other parts of the world.

\section{Aim And Objectives}

The aim of the study was to present Iyol-genen as psychotic-like reaction syndrome in Tiv social and it's predominant among the women for which reason it is not yet known even though it has genetic trait linkage according to patient who suffered it. The objectives:

1. To appraisethe concept of cultural bound-syndrome in Iyol-genen and report it peculiar epidemiology among women in Tiv culture.

2. To describe and increase awareness about culture-bound syndromes to the existing literatures.

3. To justify that Iyol-genen is an acquired genetic trait that predisposes women in some families to the disorder in Tiv culture.

\section{Research Design}

\section{Methods}

This study adopted a qualitative approach (interview) of the female folk in a general survey design to investigate and appraise the concept of a labelled cultural-bound syndrome Iyol-genen which is known and is observed to affect only women in all parts of the Tiv society irrespective of their geographical location. The focus was to identify, explore and describe this psychotic-like reactive disorder a phenomenon which little is known of why and what precipitate its prevalence among women. No attempt was made to manipulate the patients studied. The result of study could act as baseline information to determine the need for further research to understand Iyol-genen as CBS and to develop treatment mechanism to reduce its occurrence and of course the transmission to future generation of families in Tiv society.

\section{Participants}

The study participants consisted of females who met the sampling criteria and consent to participate in the study. The socio-demographic characteristics include their local government area, educational and religious background, marital status and which age range was from 13 to 35 . The sampling criteria were exclusive to women as they are the only group observed to manifest this transient abnormal behaviour in Tiv society. This is those that are occasionally experiencing Iyol-genen. A total of 40 women known or found as sufferers were contacted in their various homes including those who were admitted as in-patient though for different medical illness as well as outpatient coming for psychiatric assessment and treatment in the psychiatric unit of the Federal Medical Centre Makurdi participated to provide information for study. To protect the rights of the participants and ensure that the standard of scientific enquiry was maintained, respondents were provided with information for informed consent; that participation was voluntary and that they were to withdraw from participation if they feel so. For ensure privacy and confidentiality respondents were assured that their name and information provided will not to be mentioned or listed exception abbreviations of their names where necessary 
in a summary of the interview reported in the research. Besides, any volunteer who was experiencing or expressing her emotional discomfort either verbally or non-verbally was offered counselling.

\section{Instrument}

The women who met the selection criteria and agreed to participate in the study were interviewed individually. An interview guide was drawn and used to elicit information on their experience of this disorder overtime. The tool consisted of open-ended questions. Clearly, some questions required factual information that must eliminate the researcher's subjective opinion.

The interview guide consisted of two sections which were; first to collect demographic data such as the respondent's age group, marital status, local government area, educational and religious background. While in the next section respondents were asked questions to elicit information on their knowledge and experience of Iyol-genen disorder. Data were collected over a period of one year.

\section{Results}

Five selected cases out of the 40 cases from 5 Tiv Local Government Areas studied across the two major senatorial district in Benue state are presented for analytical purposes.

Case 1:

L. T. is an 18 years old girl secondary school student from Guma local government area. Her first episode of Iyol-genen was in May, 2012 and school before her senior secondary school examination. She has never had any history of illness or developmental disorder until one day she started experiencingusual heat in the body, severe chest pain and strings of tears rolling down from her eyes. She became restless, shouting, screaming and started running away. When her brothers caught she began to struggle and kicking to free from the hold of relatives who saw her strange sudden abnormal behaviour. There is a history of the disorder in the family as she reported that her sibling also a girl and other ones from the paternal side are victims. At all the time of occurrence she will be given holy water to drink and she is as she drinks it. But she is not sure if it is the holy water that stops it.

\section{Case 2:}

K.D. is a 19 years old girl from Katsina -Ala local government. She had her first experience of Iyolgenen on the 15/04/2011. Prior to its occurrence, she had headache, choking chest pain, aching teeth followed by some bizzare behaviour such as speaking to self, picking and throwing stones to imaginary enemy, restless, shouting, screaming and crying, sees spirit that gives her instructions and command to become a soothsayer, reveal acts of mbatsav (witches and wizard) and persons that practice tsav (Witchcraft). At episode she lost touch with reality. She feels that the attack comes naturally but during an episode she accused her eldest uncle for inflicting her with the condition. She is always given holy water or squeezed sap of "Vambe" (leaves of a particular tree that is also used for soup making). There is a history of the disorder in the family as her sibling too suffers it.

\section{Case 3:}

S. J. is 16 years old girl from Kwande local government. She drop-out of school as a result of Iyolgenen. Her first episode came when she was stung by a wasp. At each impending episode which she will be aware she began to have headache, chest pain. When the attack comes she become mute, sometimes she will be shouting and screaming and walking or running to no specific direction. She struggle and kick to free herself from hold of relations. Given mixed powdery charcoal in water or holy water at some times to drink as treatment remedy. In many episodes holy water worsened it. Trace disorder to family history.

\section{Case 4:}

N.A. and N.A. are identical twin sisters and 34 years old. Born in Makurdi but are all married with children experiences Iyol-genen occasionally. The attack to one at any time of the day triggered by loud sound of object or piercing shout of a person nearby result to the other too to react. They manifest similar signs and symptoms reported by other respondents interviewed. General folk medicine administered for remedy has been "Vambe" sap obtained from squeezing it in a bow of water.

A.I. and I.T are from Mbaduku, Vandeikya local government. A.I. is 35 years old and I.T 31 years both married with children. At age of 12 A.I. started experiencing Iyol-Genen which occasionally occurred anywhere and at any time of day. I.T. manifested similar behavioural signs and symptoms of stripping off clothes, running away to any direction they face, shouting, screaming and fighting to free from hold. Both family background have their sisters suffered the same problem at sometimes in lives. Relief was spontaneous, while at other times they are given vambe. 


\section{Discussion}

The concept of cultural-bound syndrome in mental health is absolutely real. When the term 'culturebound' syndromes was initially suggested by Yap (1967), based on the descriptive approach of 'comparative psychiatry he thought that each syndrome was bound to a particular culture or ethnic group. And this is found to be true and existing in western societies, Asia, and Africa, in Nigeria and particularly the contemporary Tiv ethnic group or culture where only females of particular age and some families are disturbed by "Iyol-genen" disorder.

On a detail appraisal and analysis of the cases presented, it is understood that Iyol-genen is not exclusively culturally bound, but is also a specific gender related disorder in Tiv society. Besides, it is not only related to the accident of geographical or a particular social stress situation,folk belief and practice as emphasized by (Idumedia, 2004;Sadock\&Sodock, 2003, Prince \&Tcheng-Laroche, 1987), but significantly also has geneticlinks as reported by the participants during interviewed by identical twins, and others who confirmed some of their sisters who also experienced iyol-genen.

Iyol-genen is a sudden episodic and dramatic reaction that is characterized by disorientation and manifestation of bizzare behaviour by an individual who is usually a girl or lady married and unmarried. Occasionally this disorder is triggered when the person hears a loud piercing sound of shouting and music from a person nearby or ceremonial places. Sometimes the episode can be induced in moment of their emotional solitary and anger from external stimuli such quarrel. Most vulnerable to this disorder are teenage girls who are between the ages of 12 to 19 years old and those who above 30 years old. Most female affected with this disorder are those in transition from puberty to adulthood. According to the participants interviewed this psychotic-like reaction disorder reported that at each episode or reoccurrence last between 20 minutes to one hour. Apparently there are variations in the signs and symptoms experience by different girls and ladies as well as the occurrence of each episode. In some the reoccurrence of Iyol-genen may be once or twice in day, while to others it occursoccasionally. Irrespective of the variation in the sign and symptoms among these females, overall, itssigns and symptoms experience includes;

Heat in the body

Chest pain

Aching teeth

Disorientation

Muteness

Restlessness

Hearing of voices and seen things indescribable (auditory/visual hallucination)

Running away to no specified direction (Confusion)

Screaming and shouting

Stripping off of clothes worn

At each episode the girl or lady acts with asudden surge of energy and strength and struggle to free self from the gripsof sympathizing relations. There is also confusion and after the attack amnesia or disavowal as in boufféedélirante reported byJilek (2001). Usually, sufferers of the disorder attribute cause bysuspecting witchcraft activities from an uncle or grandfather or mother. Notwithstanding, it is clearly established from the interview with these participants that there is a history of the condition in the family as some participants are aware that their older or younger sister in the same family or a female relative from the maternal side have experience of the disorder (Iyol-genen). This of course is a reality by virtue of the fact that two different identical twins known have this disorder and they do manifest it simultaneously or at brief interval of time when the other started reacting. This shows that the disorder is a contagious reactive syndrome. Again genetic transmission is a strong factor based on the realization that females in some families in every part of Tiv society have experienced Iyol-genenat one time or the other in their life. Therefore it can be inferred that this is a genealogical phenomenon that is traceable to the ancestral relationship of the Tiv people having a unique and common ancestral background from their origination from one ancestral father "Tiv".

Strangely and eventually, Iyol-genen has no specific orthodox treatment. It is of course self-remitted. But because traditional perception of the illness lacks knowledge of the aetiology, folk medicine is frequently used as a means to remedy the condition. This is very common with Tiv and relations of the sufferers who in an effort to calm them down, they are given squeezed sap of a particular plant known as vambe, others are holy water, and grinded charcoal powder mixed in water. Therefore the elixir of these substances for instance, vambe is known to have the potency to help a person who is in a much tensed mood, while the holy water is regarded as an antidote to evil spirit which is thought or believed to possess the person at the time of manifestation of iyol-genen. Contrary to this subjective explanation about the potency of the treatment which influenced its occasional use, it could be infer that the calmness and instant recovery of a patient on the ingestion of any of these substance during an episode may be a coincidence to the mechanism of spontaneous remission that occur as result of a psycho-biological programming of reaction at a particular time. 
This is supported with the fact that in most cases the offer of these substances on other times of the episode, the person does not feel calm or recover until the biological clock of the spontaneous remission mechanism is attained.

\section{Conclusion}

Looking back, many scholars have conducted comprehensive scientific studies of culture-related specific disorders or syndromes. This has imperatively encourage the study on Iyol-genen phenomenon in Tiv culture as means to add to the knowledge of CBS in other nation with diversity in culture such as Nigeria. Culture-bound syndromes are mental disorders whose occurrence or manifestation is not only associated to cultural, social stress, folk beliefs, geographical landscape and practice as claimed by some scholars, but hereditary also plays a major role as in the case of females in Tiv which is essential for proper assessment, diagnosis and treatment using a holistic perspective.

Therefore further studies of individual cases in this cultures are needed in order to understand the biological, psychological and socio-cultural dynamics involved the disorders. Following a dynamic approach, it would be necessary to understand comprehensively the individual's personal history, including family and cultural background, genetic study, psychological development, stresses encountered and coping patterns. There is also the need to be concerned with the impact of culture on every mental disorder, not only culture-specific syndromes, to promote culturally designed therapeutic methods that will effectively produce cure or alleviation of patients with such disorders in-as- much-as medication (psychotropic drugs) does not guarantee cure.

\section{References}

[1]. Achebe C. (1986). OgbaNje. Enugu: Fourth Dimension.

[2]. Acka, K.N. (2014). Anxiety disorders. Unpublished manuscript Department of Clinical Psychology,Federal medical Centre Makurdi.

[3]. Aina, O.F. \&Morakinyo, O. (2010).Culture-bound syndromes and the neglect of cultural factors in psychopathologies among Africans. Retrieved from doi:http://dx.doi.org/10.4314/ajpsy.v14i4.4.

[4]. Aina, O.F, \&Famuyiwa, O.O. (2007).OgunOru: A traditional explanation for Nocturnal Neuropsychiatric Disturbances among the Yoruba of South West Nigeria. Transcultural Psychiatry; 44 (1):44-54

[5]. Ayorind e S. (2008).“'Okada” rider alleges theft of private part. The Punch February 1, pp5.(Ed). Punch (Nig.) Limited, Onipetesilkeja, Lagos.

[6]. Bustamante, J.A. (1969). El bouffeedelirante en nuestromedio. Revista Psiquiatrla Transcultural. (La Habana) 3:5-20.

[7]. Collomb, H. (1965).Bouffeesdelirantes en psychiatric africaine. PsychopathologieAfricaine. 1:167-239.

[8]. Diagnostic and Statistical Manual of Mental Disorders, Fourth Edition, Text Revision (2000). American Psychiatric Association.

[9]. Gillin, J. (1948). Magical fright. Psychiatry, 11, 387-400.

[10]. Guarnaccia, P.J. \&Rogler, L.H. (1999). Research on cultural bound syndrome. New Directions. American Journal of Psychiatry, 156:1322-1327

[11]. Hughes, C. C. (1998). The glossary of ‘culture-bound syndromes' in DSM-IV: Acritique. Transcultural Psychiatry, 35(3), 413421 .

[12]. Jilek, W.G. (2001). Cultural factors in psychiatry disorders. Paper presented at the 26th Congress of the World Federation for Mental Health. Retrieved from http:/www.mentalhealth.com/mag1/wolfgang.html

[13]. Jilek, W.G. \&Jilek-Aall, L. (1977).Mass Hysteria with koro symptoms in Thailand. Archive Neurologie,Neurochirurgie und Psychiatric 142: 100- 101.

[14]. Lambo, T. A. (1962). Malignant anxiety: A syndrome associated with criminal conduct in Africans. Journal of Mental Science, 108, $256-264$.

[15]. Lambo, T.A. (1960). Further neuropsychiatric observations in Nigeria. British Medical Journal2: 1-24.

[16]. Lin, T.-Y. (Eds.). Mental Health Research in Asia and the Pacific. East - West - Center Press: Honolulu; pp. 33-53.

[17]. Littlewood, R., \&Lipsedge, M. (1986). The 'culture-bound syndromes' of the dominant culture: Culture, psychopathology and biomedicine. In J. L. Cox (Ed.), Transcultural psychiatry (pp. 253-273). London: Croom Helm.

[18]. Makanjuola, R.O.A. (1987). "Ode Ori”. A cultural Bound disorder with prominent somatic features in Yoruba Nigerian Patients. Acta PsychiatricaScandinavica; 75: 231-236

[19]. Majudina, M.Z.\&Attah-Johnson, F.Y. (1984). Standardized assessment of depressive disorder (SADD) in Ghana. Transcult Psychiatric ResRev.; 21:201-202.

[20]. Magnan, V. (1886); cK.Ey. H.; Bernard, P.; Brisset, C. (1963). Manuel de Psychiatrie. 2nd.rev.edn. Masson: Paris. p. 245.

[21]. Murphy, D. (2006). Psychiatry in the Scientific Image, Cambridge: MIT Press.

[22]. Ola, B.A. \&Igbokwe, D.O. (2012).Brain Fag Syndrome (BFS), sleep, and beliefs about sleep among secondary school students in Nigeria. ASEAN Journal of Psychiatry, Vol. 13 (2).

[23]. Prince, R. H. (1960). The 'brain fag' syndrome in Nigerian students. Journal of Mental Science, 104, 559-570.

[24]. Paniagua, F.A. (2000). Culture-bound syndromes, cultural variations, and psychopathology. In J. Cuellar \& F.A. Paniagua (Eds.), Handbook of multicultural mental health: Assessment and treatment of diverse populations (pp139-169). New York: Academic Press.

[25]. Prince, R. H., \&Tcheng-Laroche, F. (1987). Culture-bound syndromes and International Disease Classifications. Culture, Medicine and Psychiatry, $\quad 11,3-19$.

[26]. Pfeiffer,W. M. (1982). Culture-bound syndromes. In I. Al-Issa (Ed.), Culture and psychopathology (pp. 201-218). Baltimore, MD: University Park Press.

[27]. Rainaut. J. (1958). Un aspect des psychoses transitoires en milieu africain: la bouffeeaigueconfusionelle et anxieuse. In: CCTA/CSA - WFMH - WHO Meeting of Specialists on Mental Health. Bukavu, pp.193-214. 
[28]. Sadock, B.J.\&Sodock, V.A. (2003). Anthropology and cross-cultural Psychiatry. Culture Bound Syndromes (eds.) In: Kaplan \& Sadock's Synopsis of Psychiatry. Behavioural Sciences/Clinical Psychiatry. Ninth Edition. Lippincott Williams \& Wilkins: pp 166-170, 529-533

[29]. Salles, P. (1961). Aspects praffques des pschosesaiguestransitoires chez le noir d'Afriquecentrale. MedecineTropicale. 21: 1 -10.

[30]. Tseng W.S. (2006).From Peculiar Psychiatric Disorders through Culture-bound Syndromes to Culture-related Specific

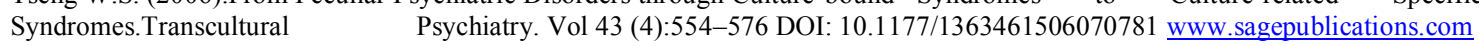

[31]. Villaseilor B.\&Sergio, J. (1993) El concepto de la "bouffeedelirante" dentro de lasclasificaciones de lasenfermedadesmentales. Revistadel Residente de Psiquiatria(Mexico). 4:26-30.

[32]. Vyncke, J. (1957). Psychoses et neuroses en Afrique centrals. Academia royale des sciences coloniales, Classe des sciences naturelleset medicates: Bruxelles.

[33]. Yap, P.M. (1969a). Classification of the culture - bound reactive syndromes. Far East Medical Joumal. 7: $219-225$.

[34]. Yap, P.M. (1969b). The culture - bound reactive syndromes. In: Caudill, W.; Lin, T.-Y. (Eds.). Mental Health Research in Asia and the Pacific. East - West - Centre Press: Honolulu; pp. 33-53. 